\title{
Rapid enzyme-mediated biotinylation for cell surface
} proteome profiling

\author{
Yanan $\mathrm{Li}^{1}$, Yan Wang ${ }^{1,2}$, Yating Yao ${ }^{1,3}$, Jiawen Lyu ${ }^{1,2}$, Qinglong Qiao ${ }^{1}$, Jiawei
}

\author{
Mao ${ }^{1}$, Zhaochao $\mathrm{Xu}^{1}$, Mingliang $\mathrm{Ye}^{1^{*}}$
}

${ }^{1}$ CAS Key Laboratory of Separation Science for Analytical Chemistry, Dalian Institute of Chemical Physics, Chinese Academy of Sciences (CAS), Dalian, 116023, China

${ }^{2}$ University of Chinese Academy of Sciences, Beijing, 100049, China

${ }^{3}$ Present address, Academy of Medical Science of Zhengzhou University, Zhengzhou University, Zhengzhou 450000, China

*To whom correspondence should be addressed: (M.L. Ye) Phone: +86-411-84379610. Fax: +86411-84379620. E-mail: mingliang@dicp.ac.cn.

This PDF file includes:

\section{Reagents and Material}

Supplementary Methods

Supplementary Results and Discussion

Evaluation of biotinylation performance of PECSL technology and amine-reactive cell surface labeling for different labeling times

Workflow optimization of PECSL technology for HeLa cell surfaceome profiling

\section{Supplementary Figures}

Figure S1 Evaluation of biotinylation performance of PECSL technology and aminereactive cell surface labeling for different labeling times.

Figure S2 The number of unique peptides and PSMs of plasma membrane proteins were analyzed for the HeLa surfaceome data.

Figure S3 Workflow optimization of PECSL technology for HeLa cell surfaceome profiling.

Figure S4 Distribution of transmembrane domains (TMDs) of transmembrane proteins (TMPs) in the PECSL data and global proteomic data in HeLa cells.

Figure S5 Assessment of the biotinylation of experimental $\left(\mathrm{H}_{2} \mathrm{O}_{2}\right.$ treatment for $\left.1 \mathrm{~min}\right)$ and negative (with $\mathrm{H}_{2} \mathrm{O}_{2}$ treatment) control cell samples using western blotting and the gel after protein transfer was stained by Coomassie Brilliant Blue method as protein level control.

Figure S6 The bar charts to show the intensities of quantified insulin-regulated proteins by PECSL technology and amine-reactive cell surface biotinyaltion.

Figure S7 String analysis for the 'early' and 'late' insulin-regulated proteins.

\section{Supplementary Tables}

Table S4 The peptide recovery assessment for $1 \mathrm{mg}$ labeled HeLa cell samples by PECSL technology. 
Table S7 The PECSL data and multiple surfaceome data generated by using different enrichment strategies were analyzed with SurfaceGenie.

\section{References}

Other supplementary materials for this manuscript include the following:

Table S1 The identification information of HeLa surfaceome data by PECSL labeling and amine-reactive cell surface labeling with different labeling times.

Table S2 Label-free quantification (LFQ) information for the pulldown proteins between the control (without BxxP) and experimental $(200 \mu \mathrm{M} B \times \times P)$ cell samples and GO enrichment analysis for the up-regulated proteins ( $p$-value $<0.05, \geq 2$-fold) of the pulldown samples in the experimental versus control (without BxxP) groups.

Table S3 Label-free quantification (LFQ) information for whole lysate proteins between the control (without $\mathrm{H}_{2} \mathrm{O}_{2}$ ) and experimental $\left(1 \mathrm{mM} \mathrm{H}_{2} \mathrm{O}_{2}\right.$ ) groups cell samples and String analysis for the up-regulated proteins ( $\mathrm{p}$-value $<0.05, \geq 2$-fold) of whole lysate samples in the experimental versus control (without $\mathrm{H}_{2} \mathrm{O}_{2}$ ) groups.

Table S5 List of the proteins identified by PECSL technology and global proteomic approach.

Table S6 GO enrichment analysis was performed for the PECSL data according to cellular component and proteins identified by the global proteomic approach were set as the reference gene list.

Table S8 Label-free quantification (LFQ) information for the enriched proteins between the experimental and control (without $\mathrm{H}_{2} \mathrm{O} 2$ treatment) cell samples.

Table S9 Surfaceome quantification information by PECSL technology and aminereactive cell surface biotinylation method after insulin treatment.

Table S10 GO enrichment analysis of 'early' (5 min) and 'late' (2 h) insulin-regulated proteins according to biological process. 


\section{REAGENTS AND MATERIALS}

Alexa Fluor ${ }^{\mathrm{TM}} 488$ conjugated goat anti-rabbit $\mathrm{IgG}(\mathrm{H}+\mathrm{L})$ highly cross-adsorbed secondary antibody, Alexa Fluor ${ }^{\mathrm{TM}} 568$ conjugated streptavidin, EZ-Link ${ }^{\mathrm{TM}}$ Sulfo-NHS-SS-biotin, Pierce ${ }^{\mathrm{TM}}$ $660 \mathrm{~nm}$ protein assay reagent, goat serum, 30\% hydrogen peroxide $\left(\mathrm{H}_{2} \mathrm{O}_{2}\right)$, 4',6-diamidino-2phenylindole (DAPI), and neutravidin agarose resin were purchased from Thermo Fisher Scientific (Waltham, MA, USA). Biotin- $x \times$-phenol probe (BxxP, biotin-C6-C6-tyramine) was synthesized by Chinese peptide company. The antibodies of TFRC and GAPDH were purchased from Proteintech and the antibody of streptavidin-HRP were from cell-signaling technology. Sodium dodecyl sulfate (SDS), protease inhibitor cocktail, $( \pm$ )-6-Hydroxy-2,5,7,8-tetramethylchromane-2-carboxylic acid (Trolox), sodium ascorbate, sodium azide, sodium deoxycholate, HRP [150-250 units/mg solid (using pyrogallol)], hydrogen peroxide solution ( $30 \%$ (w/w) in $\mathrm{H}_{2} \mathrm{O}$ ), protease inhibitor cocktail, trifluoroacetic acid (TFA), dithiothreitol (DTT), iodoacetamide (IAA), sodium chloride ( $\mathrm{NaCl}$ ), ammonium bicarbonate (ABC), sodium phosphate dibasic, Triton X-100, insulin solution human, and trypsin (bovine, TPCK-treated) were obtained from Sigma-Aldrich (St. Louis, MO, USA). Formic acid (FA) was obtained from Fluka (Buches, Germany). Acetonitrile (ACN, HPLC grade) and methanol (HPLC grade) was from Merck (Darmstadt, Germany). Tween-20, tris, and glycine were purchased from BBI life sciences. Other chemicals and reagents were either of analytical grade or a better grade. Pure water used in all experiments was purified with a Milli-Q system (Millipore, Milford, MA).

\section{SUPPLEMENTARY METHODS}

\section{Amine-reactive cell surface labeling and cell lysis}

For amine-reactive cell surface labeling, cell-surface proteins were biotinylated by covalently coupling with primary amines via EZ-Link ${ }^{\mathrm{TM}}$ Sulfo-NHS-SS-biotin and isolated as described before $^{1}$. Briefly, HeLa cells at about $80 \%$ confluency were subjected to media removal and three washes with PBS, followed by the incubation with PBS containing $0.25 \mathrm{mg} / \mathrm{ml}(\sim 411 \mu \mathrm{M})$ or 1.0 $\mathrm{mg} / \mathrm{ml}(\sim 1.65 \mathrm{mM})$ EZ-Link ${ }^{\mathrm{TM}}$ Sulfo-NHS-SS-biotin for pre-determined time points $(10 \mathrm{~s}, 30 \mathrm{~s}, 2$ min, $5 \mathrm{~min}, 10 \mathrm{~min}$, and $30 \mathrm{~min}$ ) at room temperature. In the meantime, PBS and labeling buffer were room temperature-warmed. Next, labeling reaction was quenched with ice-cold PBS containing $100 \mathrm{mM}$ glycine, followed by two washes with ice-cold tris-buffered saline (TBS, 20 $\mathrm{mM}$ tris, $150 \mathrm{mM}$ sodium chloride, $\mathrm{pH}$ 7.4). Afterwards, ice-cold strong RIPA lysis buffer containing $0.2 \%(\mathrm{v} / \mathrm{v})$ protease inhibitor cocktail was added. The cells were harvested by scraping on ice and lysed by sonication with $10 \times 30 \mathrm{~s}$ pulsed (high) and centrifuged at $16000 \times \mathrm{g}$ for $15 \mathrm{~min}$ at $4{ }^{\circ} \mathrm{C}$. The protein concentration of the clarified supernatant was determined by BCA protein assay.

\section{Western blotting}

$20 \mu \mathrm{g}$ of labeled HeLa cell lysate was re-dissolved in reducing SDS-polyacrylamide gel electrophoresis (SDS-PAGE) sample buffer for PECSL labeling and non-reducing SDS-PAGE sample buffer for Sulfo-NHS-SS-biotin labeling. Then the proteins on the gel were transferred onto a PVDF membrane $(0.45 \mu \mathrm{m}$, Millipore $)$, which was then blocked with the buffer of $5 \%$ skimmed milk in TBST $(0.1 \%$ Tween-20, $150 \mathrm{mM} \mathrm{NaCl}, 20 \mathrm{mM}$ Tris-HCl, $\mathrm{pH} 8.0)$ for $2 \mathrm{~h}$ at room temperature. Next, the membrane was then incubated with HRP-labeled streptavidin diluted 1:4000 in the blocking buffer overnight at $4^{\circ} \mathrm{C}$. After three washes with TBST, HRP substrates (Pierce ${ }^{\mathrm{TM}}$ ECL western blotting substrate) were added, and the bands were detected by BioImaging systems (Fusion FX5-XT). To evaluate protein loading amount for the samples, after blocking procedure, 
the membrane was incubated with primary antibodies (GAPDH diluted 1: 5000 in blocking buffer) overnight at $4{ }^{\circ} \mathrm{C}$. After three washes with TBST, the membrane was incubated with relevant HRPlabeled secondary antibody diluted 1:10000 in blocking buffer for $2 \mathrm{~h}$ at room temperature. Finally, after three washes with TBST, HRP substrates were added and the bands were detected by BioImaging systems.

\section{Immunofluorescence assay}

To evaluate the selectivity of PECSL strategy for cell-surface labeling, living HeLa cells were labeled by PECSL labeling for $1 \mathrm{~min}$ at room temperature and fixed with $4 \%$ formaldehyde in PBS at room temperature for $15 \mathrm{~min}$. After three washes with PBS, the cells were permeabilized with $0.2 \%$ Triton X-100 in PBS for $5 \mathrm{~min}$ at room temperature. After three washes with PBS, the cells were blocked with $10 \%$ goat serum in PBS for one hour at room temperature and then incubated with $2 \mu \mathrm{g} / \mathrm{ml}$ Alexa Fluor ${ }^{\mathrm{TM}} 568$ conjugated streptavidin and $1 \%$ in PBS overnight at $4^{\circ} \mathrm{C}$ under the protection from light, which was required for all the following procedures goat serum. Subsequently, after four washes with PBST (PBS, 0.05\% Tween-20), the cells were then incubated with $1 \mu \mathrm{g} / \mathrm{ml}$ DAPI in PBS at room temperature for $1 \mathrm{~h}$. After three washes with PBST, the cells were analyzed using the ANDOR ${ }^{\mathrm{TM}}$ living cell laser scanning confocal microscope (Revolution WD).

To verify the dynamic changes of protein abundance on the plasma membrane upon insulin exposure, the serum-starved HepG2 cells were further treated with $37^{\circ} \mathrm{C}$ pre-warmed media containing $200 \mathrm{nM}$ insulin or $37^{\circ} \mathrm{C}$ pre-warmed insulin-free media for $5 \min$ or $2 \mathrm{~h}$ at $37^{\circ} \mathrm{C}$. Immediately, PECSL labeling was performed for $1 \mathrm{~min}$ at room temperature, followed by the addition of ice-cold quenching buffer. Labeled cells were then fixed with $4 \%$ formaldehyde in PBS at room temperature for $15 \mathrm{~min}$. Then, the cells were washed three times with PBS, followed by the permeabilization with $0.2 \%$ Triton X-100 in PBS for $5 \mathrm{~min}$ at room temperature. After three more washes with PBS, the cells were blocked with $10 \%$ goat serum in PBS for one hour at room temperature and then incubated with primary antibodies (TFRC diluted 1: 200 in 1\% goat serum or LRP1 diluted 1:200 in 1\% goat serum) and $1 \%$ goat serum in PBS overnight at $4{ }^{\circ} \mathrm{C}$. Subsequently, after three washes with PBST, the cells were then incubated with $2 \mu \mathrm{g} / \mathrm{ml}$ AF488-labeled secondary antibodies and $1 \%$ goat serum in PBS for 1-2 $\mathrm{h}$ at room temperature under the protection from light, which was a need for the all following procedures. Next, after three washes with PBST, the cells were then incubated with $2 \mu \mathrm{g} / \mathrm{ml}$ Alexa Fluor ${ }^{\mathrm{TM}} 568$ conjugated streptavidin and $1 \%$ goat serum in PBS for 1-2 $\mathrm{h}$ at room temperature. After four-time washes with PBST (PBS containing $0.05 \%$ Tween-20), the cells were then incubated with $1 \mu \mathrm{g} / \mathrm{ml}$ DAPI at room temperature for $1 \mathrm{~h}$. After three washes with PBST, the cells were analyzed using the ANDOR ${ }^{\mathrm{TM}}$ living cell laser scanning confocal microscope.

\section{Nano-RPLC-ESI-MS/MS analysis}

After protein digestion, the lyophilized peptides were re-suspended in $0.1 \% \mathrm{FA} / \mathrm{H}_{2} \mathrm{O}$ solution and analyzed using a Dionex UltiMate 3000 RSLCnano system with a Q-Exactive mass spectrometer, controlled by Xcalibur software v2.1.0 (Thermo Fisher Scientific, Waltham, MA, USA). About 1$2 \mu \mathrm{g}$ of each peptide sample was automatically injected onto an in-house packed 3-cm trap column (150 $\mu \mathrm{m}$ i.d, $1.9 \mu \mathrm{m} \mathrm{C18} \mathrm{AQ} \mathrm{particles)} \mathrm{at} \mathrm{a} \mathrm{flow} \mathrm{rate} \mathrm{of} 5 \mu \mathrm{l} / \mathrm{min}$ and eluted with a gradient program performed as follows: $9 \%$ - 35\% B in $90 \mathrm{~min}, 35 \%$ - 45\% B in $13 \mathrm{~min}, 45 \%$ - $90 \%$ B in 2 min, hold at $90 \% \mathrm{~B}$ for $10 \mathrm{~min}$ and then re-equilibrated the column at $4 \%$ B for $15 \mathrm{~min}$. Mobile phase A contained $0.1 \%(\mathrm{v} / \mathrm{v})$ FA in water (Merck), mobile phase B contained $0.1 \%(\mathrm{v} / \mathrm{v})$ FA and $80 \%(\mathrm{v} / \mathrm{v})$ acetonitrile (ACN, HPLC grade, Merck) in water, and the flow rate for the gradient program was 
adjusted to $\sim 600 \mathrm{~nL} / \mathrm{min}$. The capillary analytical column $(150 \mu \mathrm{m}$ i.d) was prepared as follows: one end of the fused-silica capillary was first manually pulled to a fine point as a spray tip and then packed in-house with C18 AQ particles $(1.9 \mu \mathrm{m})$ to $10 \mathrm{~cm}$.

The electrospray ionization tandem mass spectrometer (ESI-MS/MS) was operated in datadependent MS/MS acquisition mode with a spray voltage of $2.6 \mathrm{kV}$ and an ion transfer capillary temperature of $275^{\circ} \mathrm{C}$. The full mass scan acquired in the Orbitrap mass analyzer was from $\mathrm{m} / \mathrm{z} 350$ to 1750 with a resolution of 70000 . The 15 most intense parent ions with charge states $2-6$ from the full scan were fragmented by higher energy collisional dissociation (HCD). The MS/MS scans were also acquired by the Orbitrap with a 17500 resolution, and the AGC target was set to $1 \times 10^{5}$. The normalized collisional energy for HCD was set $27 \%$. Dynamic exclusion was set as $30 \mathrm{~s}$, and the maximum allowed ion accumulation time was $100 \mathrm{~ms}$ for MS scans and $60 \mathrm{~ms}$ for MS/MS.

\section{Data searching}

For protein identification, MS raw data files were analyzed using Proteome Discoverer (Thermo Scientific, v2.1.1.21) incorporated with mascot 2.5 (Matrix Science Inc) search engine against a non-redundant UniProt human database (containing 20325 sequences, and downloaded from www.uniprot.org). The search parameters were set to be as follows: trypsin as the specific proteolytic enzyme, two missed cleavage sites, carbamidomethyl (C) as a static modification and oxidation (M) as a variable modification, $10 \mathrm{ppm}$ for precursor-ion mass tolerance, $0.05 \mathrm{Da}$ for fragment-ion mass tolerance. In addition, for amine-reactive cell surface biotinylation, thioacylation ( $\mathrm{K}$ and protein $\mathrm{N}$-term) and carbamidomethylthio-propanothylation ( $\mathrm{K}$ and protein $\mathrm{N}$-term) were set as additional variable modifications. The false discovery rate (FDR) was controlled to $<1 \%$ in every search result and proteins with a score less than 20 were discarded. The decoy database was generated by Mascot. The other settings were the same as the conventional search.

For protein quantification, the raw data files were analyzed using the software of MaxQuant v1.5.2.8. The search parameters were set as follows: trypsin as the specific proteolytic enzyme, two missed cleavage sites, carbamidomethyl (C) as a static modification and oxidation (M) as a variable modification, minimum 2 unique peptides for protein identification, PSM FDR (peptide-spectrum match false discovery rate) $1 \%$, and protein FDR 1\%. For identification, "Min. peptides", "Min ratio + unique peptides", "Min. unique peptides" were set as 2, 2, 1. The other settings were the same as the conventional search. The database search was performed against a non-redundant UniProt human database (containing 20325 sequences, and downloaded from www.uniprot.org) using Andromeda search engine integrated into the MaxQuant environment.

LFQ data was then analyzed using Perseus software. The reverse hits, potential contaminant hits, and hits that only identified by site were removed for further analysis. To compare pulldown proteins between $\mathrm{B} \times \times \mathrm{P} / \mathrm{H}_{2} \mathrm{O}_{2}$ treatment and un-treatment cell samples, or whole lysate proteins between $\mathrm{H}_{2} \mathrm{O}_{2}$ treatment and un-treatment cell samples, hits were then filtered that at least one group have two values. Next, significance was assessed using t-test, permutation-based FDR for multiple hypothesis testing (FDR $<0.05$ ). Hits were subsequently filtered for a fold change $\geqslant 2$ and $\mathrm{p}$ value $<0.05$ using Perseus software (Table S2-S3, S8). To profile the temporal changes of cell surface proteome after insulin exposure, hits were filtered that at least one group has seven values out of nine runs. Significance was assessed using t-test, Benjamini-Hochberg FDR for multiple hypothesis testing (FDR $<0.05)$. Hits were subsequently filtered for a fold change $\geqslant 1.5$ and $\mathrm{p}$ value $<0.01$ (Table $\mathrm{S} 9$ ). 


\section{SUPPLEMENTARY RESULTS AND DISCUSSION}

\section{Evaluation of biotinylation performance of PECSL technology and amine-reactive cell surface labeling for different labeling times}

Here, according to previous studies ${ }^{2-3}$ and the manufacturer's instructions of cell surface protein isolation kit (Pierce, Cat\#: 21445) ${ }^{4-10}$, a concentration of $0.25 \mathrm{mg} / \mathrm{ml}$ for Sulfo-NHS-SS-biotin ( $411 \mu \mathrm{M}$, MW609.69) was first utilized to evaluate the labeling time for efficient biotinylation. In this experiment, $4 \mathrm{~mL}$ of $0.25 \mathrm{mg} / \mathrm{ml}$ Sulfo-NHS-SS-biotin was added to a 10-cm dish of HeLa cells ( $\sim 1.5 \mathrm{mg}$ proteins). For example, when the molecular weight of the protein mixture was average $60,000 \mathrm{Da},>66$-fold molar excess of biotin was used in this experiment. Living HeLa cells were then biotinylated by PECSL labeling and amine-reactive labeling for the pre-determined time points and analyzed by streptavidin-blot and LC-MS/MS (Figure 2D-E, Figure S1A-B). The detailed description could be seen in the main manuscript. In addition, the number of unique peptides and PSMs of plasma membrane proteins (cell surface/plasma membrane) were also analyzed. As seen in Figure S2, a slightly increase of the number of PSMs (Figure S2A) and peptides (Figure S2C) of plasma membrane proteins were found for the PECSL data with prolonged labeling time from $10 \mathrm{~s}$ to $10 \mathrm{~min}$, whereas those were highly depended on the labeling time for the SulfoNHS-SS-biotin data (Figure S2B-S2D). We also found that a larger median number of PSMs and peptides of plasma membrane proteins were identified by amine-reactive cell surface biotinylation method than those by PECSL technology, which could be attribute to the differences in sample preparation step (like protein digestion) and peptide identification component. Biotinylated proteins enriched by amine-reactive labeling could be eluted by reducing reagent-containing buffers, digested via FASP (filter-aided sample preparation) protocol and the resultant labeled peptides could be identified or quantified by introducing the additional dynamic modifications of thioacylation ( $\mathrm{K}$ and protein N-term) and carbamidomethylthio (CAM)-propanoylation ( $\mathrm{K}$ and protein N-term), whereas biotinylated proteins labeled by PECSL technology were digested on-bead and the biotinylated peptides were hard to be eluted for MS identification due to the very high stability of the biotin-avidin complex $\left(\mathrm{K}_{\mathrm{d}} \sim 10^{-15} \mathrm{M}\right)$. With prolonged labeling time, cell-surface proteins tend to have a higher labeling efficiency, which is also a disadvantage to the sequence coverage for highly bitoinylated proteins for PECSL technology.

Above results demonstrated that the biotinylation by amine-reactive cell surface biotinyaltion method was highly depended on the labeling time (Figure 1D-E, Figure S2). Though the concentration of Sulfo-NHS-SS-biotin probe $(\sim 411 \mu \mathrm{M})$ used here was higher than that of $\mathrm{B} \times \times \mathrm{P}$ $(\sim 200 \mu \mathrm{M})$, we wonder that whether the labeling speed might be improved by increasing the concentration. To address this question, a much higher concentration of Sulfo-NHS-SS-biotin (1 $\mathrm{mg} / \mathrm{ml}, \sim 1.65 \mathrm{mM}$ ) was used to perform cell-surface labeling for the pre-determined time points, in the meantime, PECSL labeling was also performed in living HeLa cells for the pre-determined time points. As seen in Figure 1F, 996 cell surface-annotated proteins were identified by amine-reactive cell surface biotinylation method with a labeling time of $10 \mathrm{~s}$, indicating that a higher labeling speed of amine-reactive labeling was achieved by increasing the concentration of labeling probe to 1 $\mathrm{mg} / \mathrm{ml}$. On the other hand, western blot result demonstrated that PECSL labeling resulted in much higher biotinylation level when the labeling time was shorter than $2 \mathrm{~min}$, and amine-reactive surface labeling resulted in much higher labeling efficiency with prolonged labeling time, which was consistent with the result of Figure 1D. Though a much higher concentration of labeling probe was used here, the western blotting (Figure S1C-D) and the MS identification results (Figure S1F-G) 
also demonstrated that the biotinylation by amine-reactive labeling was still highly depended on the labeling time. In this case, when a short labeling time is essential, reproducibility could be a challenge but is crucial for quantitative comparison of surfaceomes of diverse areas of biomedical research.

\section{Workflow optimization of PECSL technology for HeLa cell surfaceome profiling}

Cell surface proteins of living HeLa cells were biotinylated by PECSL strategy, followed by cell lysis, avidin-affinity purification, on-bead digestion, and LC-MS/MS analysis. To get a better performance of PECSL technology, we carefully optimized the workflow of PECSL technology, including the concentration of labeling probes $\left(\mathrm{C}_{\mathrm{B} \times \times \mathrm{P}}\right.$, Figure $\mathrm{S} 3 \mathrm{~A}-\mathrm{D}$, Table $\left.\mathrm{S} 2\right)$, the volume of beads for a certain quality of labeled proteins (Figure S3E) and the concentration of hydrogen peroxide $\left(\mathrm{C}_{\mathrm{H} 2 \mathrm{O} 2}\right.$, Figure S3F-I, Table S3) using western blotting and single-run LC-MS/MS measurement in HeLa cells. According to previous studies ${ }^{1}, 1 \mathrm{mM}$ of $\mathrm{H}_{2} \mathrm{O}_{2}$ and $100 \mu \mathrm{M}$ labeling probe were used for PECSL labeling. And an excessive amount of $0.25 \mathrm{mg} / \mathrm{ml} \mathrm{HRP} \mathrm{final}(675 \sim 1125 \mu \mathrm{M}$ substrates per minute at $25^{\circ} \mathrm{C}$ ) was chosen for the designed PECSL strategy.

We first evaluated the optimal concentration of $\mathrm{B} \times \times \mathrm{P}$ and a series of gradient concentrations from $25 \mu \mathrm{M}$ to $500 \mu \mathrm{M}$ were used for HeLa cell surface proteome profiling. In the meantime, a negative control group, in which labeling probes was omitted, was prepared to assess the endogenous biotinylation level. As seen in Figure S3A-B, considering the identification number of cell surfaceannotated proteins and biotinylation, $200 \mu \mathrm{M}$ labeling probe of $\mathrm{B} \times \times \mathrm{P}$ was chosen for the optimized workflow. In order to further determine the enrichment of cell-surface proteins using PECSL strategy, a LFQ proteomic experiment was then employed to compare the biotinylated proteins between the control (no $\mathrm{B} \times \times \mathrm{P}$ ) and experimental $(200 \mu \mathrm{M} \mathrm{B} \times \times \mathrm{P})$ cell samples (Table S2). As seen in Figure S3C, the majority of quantified proteins after data filtering were annotated cell-surface proteins and significantly enriched in the $\mathrm{B} \times \times \mathrm{P}$-treated experimental groups. Afterwards, cellular component classification for the up-regulated proteins ( $\mathrm{p}$-value $<0.05, \geqslant 2$-fold) was conducted by GO enrichment analysis and found that cell surface-related GO-terms of "cell surface", "plasma membrane", "extracellular region", and "focal adhesion" showed significant enrichment (Figure S3C-D, Table S2), demonstrating that the good selectivity of the new labeling strategy. A proper volume of avidin beads for a certain amount of total cell lysate was then evaluated using single-run MS measurement. $3.6 \mathrm{mg}$ above labeled cell lysates were split into three parts and then purified with $20 \mu \mathrm{l}, 40 \mu \mathrm{l}$ and $75 \mu \mathrm{l}$ of neutravidin beads, respectively. In the meantime, the control cell sample was prepared, in which, hydrogen peroxide was omitted to assess the endogenous biotinylation level. As seen in Figure S3E, the larger volume of avidin beads was used, the larger number of proteins was identified in both experimental and negative control groups, whereas the less selectivity of PECSL technology was obtained. And $40 \mu \mathrm{l}$ of neutravidin beads was used for $1.2 \mathrm{mg}$ of labeled cell samples $\left(\sim 4 \times 10^{6} \mathrm{HeLa}\right.$ cells $)$ for affinity enrichment in the optimized workflow. Finally, the optimal concentration of $\mathrm{H}_{2} \mathrm{O}_{2}$ was evaluated using both western blotting (Figure S3F) and single-run MS measurement (Figure S3G). On the one hand, $\mathrm{H}_{2} \mathrm{O}_{2}$ serves as oxidant and therefore is essential for the catalytic action. On the other hand, if the concentration of $\mathrm{H}_{2} \mathrm{O}_{2}$ is too high, oxidation could be inhibited ${ }^{11}$. In addition, $\mathrm{H}_{2} \mathrm{O}_{2}$ treatment on living cells could lead to undesired cytotoxicity arising from oxidative stress signaling ${ }^{6}$. Therefore, restricting $\mathrm{H}_{2} \mathrm{O}_{2}$ labeling to low concentrations and short time windows is crucial for minimizing side effects. As seen in Figure S3G, consistent number of cell-surface proteins were identified with a final concentration of $\mathrm{H}_{2} \mathrm{O}_{2}$ from $1 \mathrm{mM}$ to $10 \mathrm{mM}$. And the concentration of $1 \mathrm{mM} \mathrm{H}_{2} \mathrm{O}_{2}$ final was chosen 
for the optimized workflow. In addition, to assess the oxidative damage from 1 min incubation with $1 \mathrm{mM} \mathrm{H}_{2} \mathrm{O}_{2}$ on the biological processes, a LFQ proteomic experiment was then employed to compare the total protein lysates between the control (without $\mathrm{H}_{2} \mathrm{O}_{2}$ treatment) and experimental (1 $\mathrm{mM} \mathrm{H} \mathrm{H}_{2} \mathrm{O}_{2}$ treated for $1 \mathrm{~min}$ ) cell samples (Table $\mathrm{S} 3$ ). As seen in Figure $\mathrm{S} 3 \mathrm{H}, 42$ proteins were significantly up-regulated (p-value $<0.05, \geqslant 2$-fold) after $\mathrm{H}_{2} \mathrm{O}_{2}$ treatment. For the 42 proteins, string analysis was performed to illustrate known and predicted functional interactions by the software of Cytoscape and found that biological processes of "rRNA processing", "DNA packaging" and "angiogenesis" were significantly enriched (p-value < 0.05, Figure S3I, Table S3). Overall, the optimum experimental conditions were listed in Figure S3J.

293

294 
A

PECSL technology

Biotin labeling: room temperature

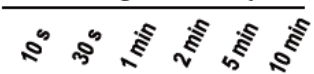

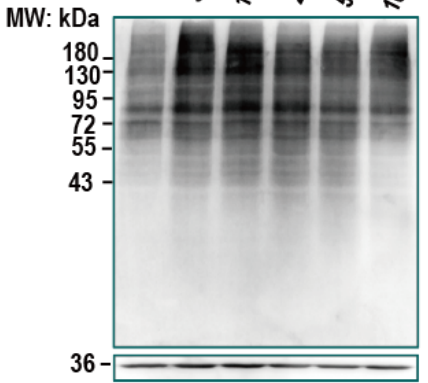

$\mathrm{C}$

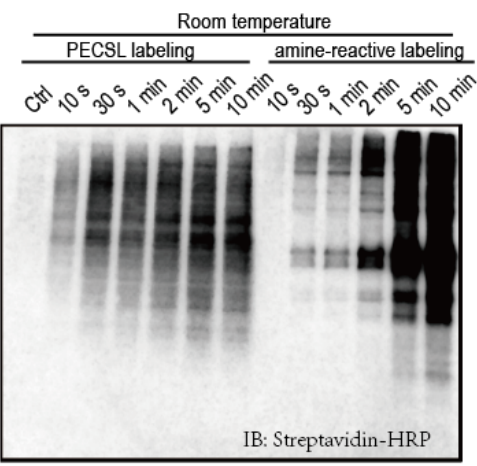

Ctrl: negative control, without $\mathrm{H}_{2} \mathrm{O}_{2}$ treatment

PECSL labeling: $\sim 200 \mu \mathrm{M} \mathrm{Bx \times P}$, reducing loading buffer

Amine-reactive labeling: $1 \mathrm{mg} / \mathrm{ml}$ Sulfo-NHS-SS-biotin $(\sim 1.65 \mathrm{mM})$, non-reducing loading buffer

$\mathrm{E}$
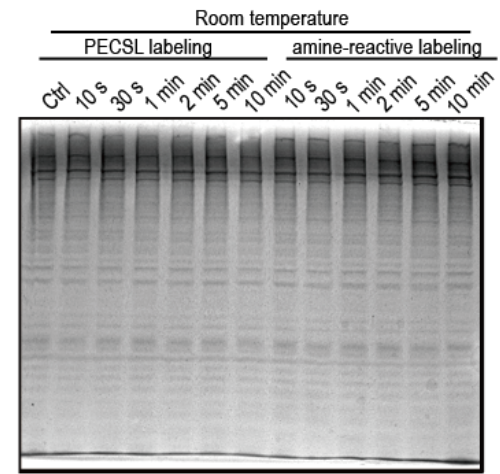

SDS-PAGE for the gel after protein tranfer Ctrl: negative control, without $\mathrm{H}_{2} \mathrm{O}_{2}$ treatment

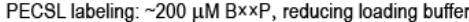
Amine-reactive labeling: $1 \mathrm{mg} / \mathrm{ml}$ Sulfo-NHS-SS-biotin $(\sim 1.65 \mathrm{mM})$,

G

\begin{tabular}{|c|c|c|c|c|c|c|c|}
\hline \multicolumn{2}{|c|}{$\begin{array}{c}\text { Amine-reactive cell surface } \\
\text { biotinylation }\end{array}$} & $10 \mathrm{~s}$ & $30 \mathrm{~s}$ & $1 \mathrm{~min}$ & $2 \mathrm{~min}$ & $5 \mathrm{~min}$ & $10 \mathrm{~min}$ \\
\hline \multirow{2}{*}{ Total } & Unique peptides & 11852 & 15426 & 16198 & 19767 & 20853 & 22946 \\
\cline { 2 - 8 } & proteins & 1794 & 2200 & 2301 & 2755 & 2958 & 3202 \\
\hline \multirow{2}{*}{ Cell surface-annotated proteins } & 996 & 1161 & 1209 & 1336 & 1411 & 1448 \\
\hline \multirow{2}{*}{ biotinylated } & Unique peptides & 96 & 239 & 254 & 402 & 916 & 1420 \\
\cline { 2 - 8 } & proteins & 64 & 129 & 138 & 192 & 378 & 485 \\
\hline
\end{tabular}

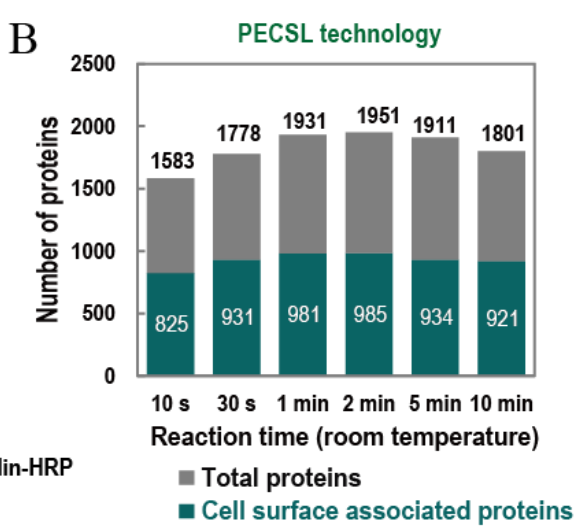

$\mathrm{D}$

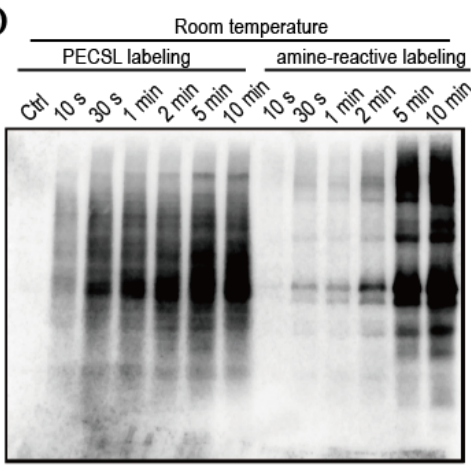

Ctrl: negative control, without $\mathrm{H}_{2} \mathrm{O}_{2}$ treatment

PECSL labeling: $\sim 200 \mu \mathrm{M} \mathrm{B \times PP}$, non-reducing loading buffer

Amine-reactive labeling: $1 \mathrm{mg} / \mathrm{ml}$ Sulfo-NHS-SS-biotin ( 1.65 mM), non-reducing loading buffer

$\mathrm{F}$

Amine-reactive cell surface biotinyaltion

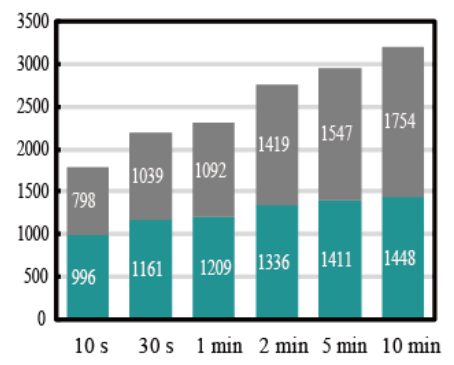

- Cell surface-annotated proteins wother proteins

Amine-reactive labeling: $1 \mathrm{mg} / \mathrm{ml}$ Sulfo-NHS-SS-biotin $(\sim 1.65 \mathrm{mM})$

Figure S1: Evaluation of biotinylation performance of PECSL technology and amine-reactive cell surface labeling for different labeling times. The enzymatic biotin labeling time was assessed at room temperature for efficient cell-surface labeling by PECSL technology using $(A)$ western blotting and $(B)$ single-run LC-MS/MS measurement. ( $C-G)$ Comparison the biotinylation by PECSL labeling and amine-reactive labeling at room temperature using streptavidin-HRP blot. A 
much high concentration of Sulfo-NHS-SS-biotin $(1.0 \mathrm{mg} / \mathrm{ml}, \sim 1.65 \mathrm{mM})$ for amine-reactive labeling was utilized. Due to the presence of disulfide bridge in the labeling reagent of amine-reactive labeling, it could be cleaved in the reducing environment. And the sample loading buffer for aminereactive labeling $(C, D)$ was without reducing reagent like DTT (Pierce ${ }^{\mathrm{TM}}$ Lane Marker NonReducing Sample Buffer, cat\#39001). But the sample loading buffer for PECSL labeling $(A, C)$ was in a reducing formulation (Pierce ${ }^{\mathrm{TM}}$ Lane Marker Reducing Sample Buffer, cat\#39000). (D) the sample loading buffer for amine-reactive labeling and PECSL labeling was without reducing reagent like DTT. $(E)$ The gel after protein transfer was stained by Coomassie Brilliant Blue method as protein level control. $(F-G)$ Biotinylated proteins by amine-reactive cell surface labeling for the predetermined time points were analyzed by single-run LC-MS/MS measurement. 
A

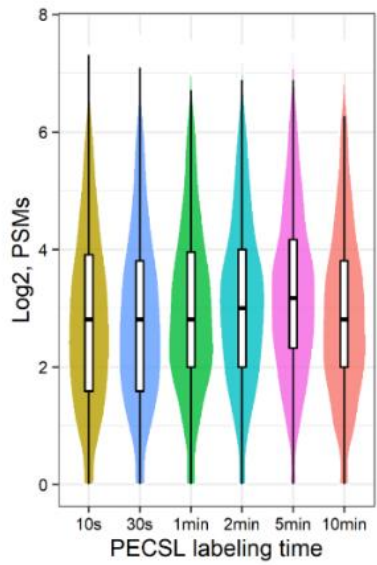

C

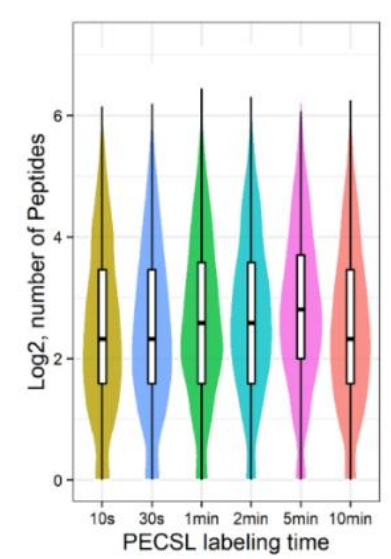

B

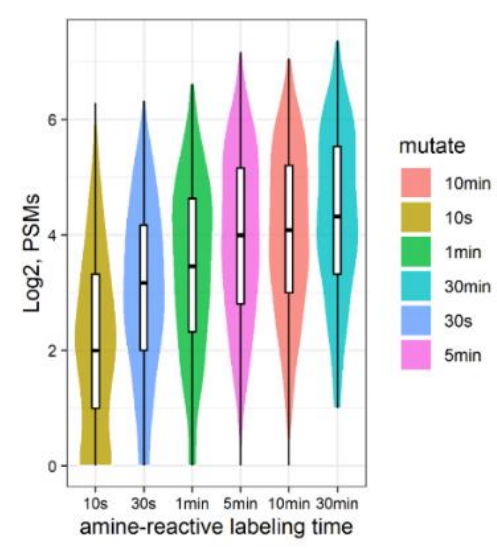

D

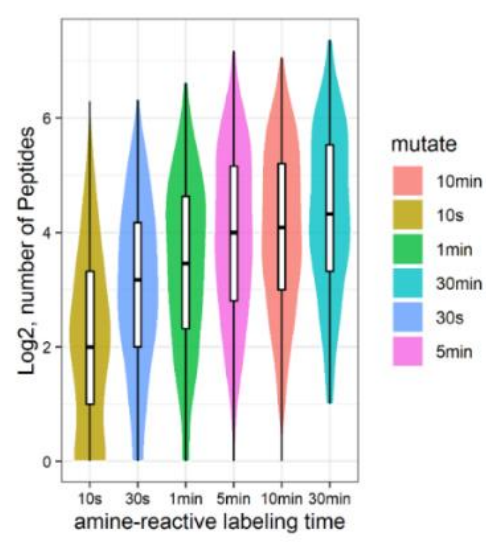

Figure S2: The number of unique peptides and PSMs of plasma membrane proteins were analyzed for the HeLa surfaceome data. Living HeLa cells were biotinylated by PECSL labeling and amine-reactive labeling for the pre-determined time points and then analyzed by LC-MS/MS. The number of $(A, B)$ PSMs and $(C, D)$ unique peptides of the identified plasma membrane proteins (cell surface/plasma membrane) were analyzed. 
A

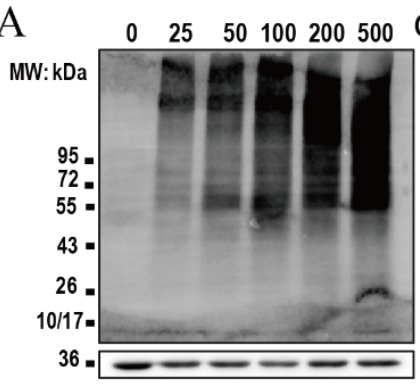

C

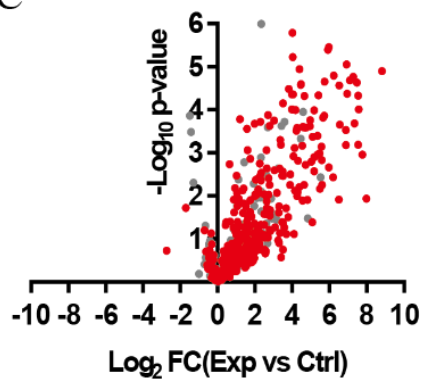

- Cell surface-annotated proteins

- other proteins

E

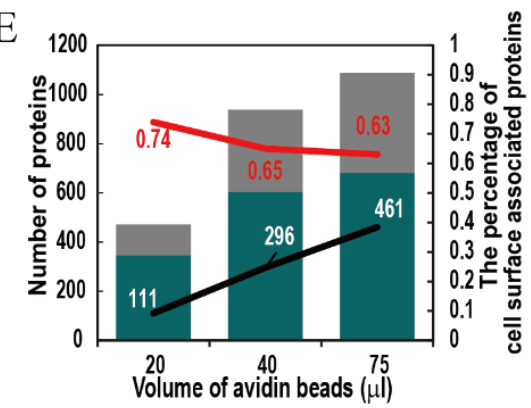

-Total proteins

- Cell surface-annotated proteins

-Total proteins identified in control group

G -The percentage of cell surface-annotated proteins
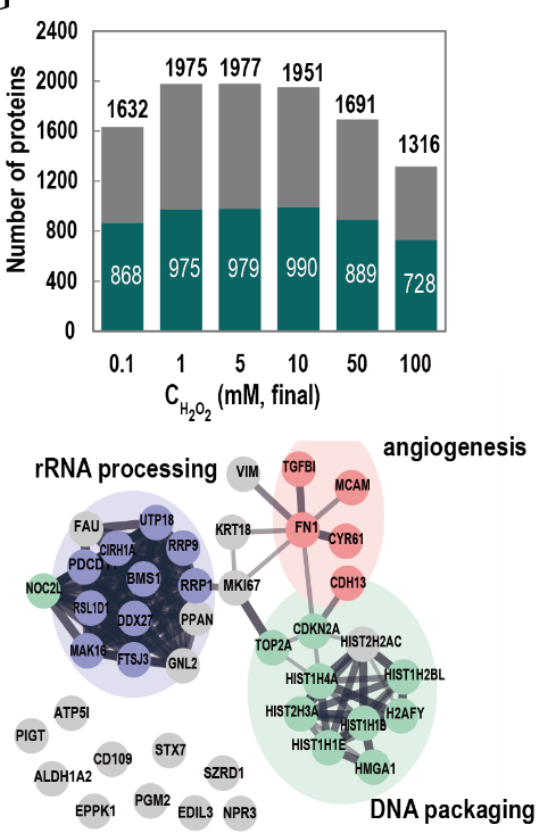

B

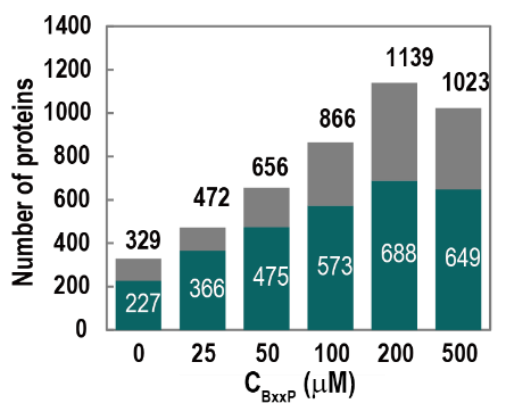

D

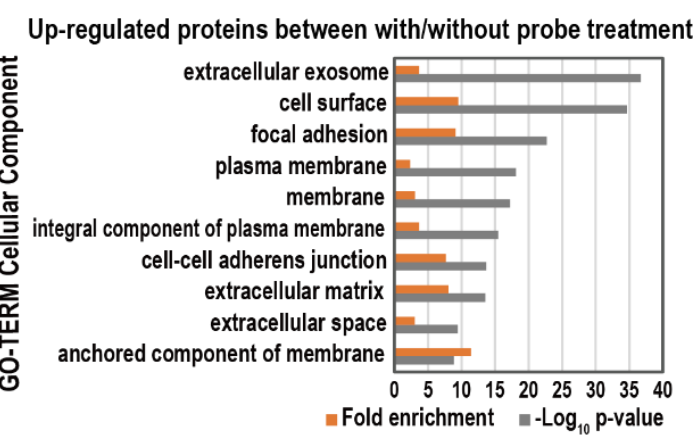

F

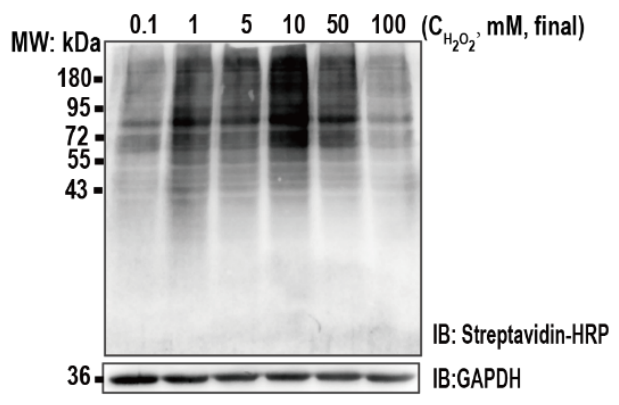

$\mathrm{H}$

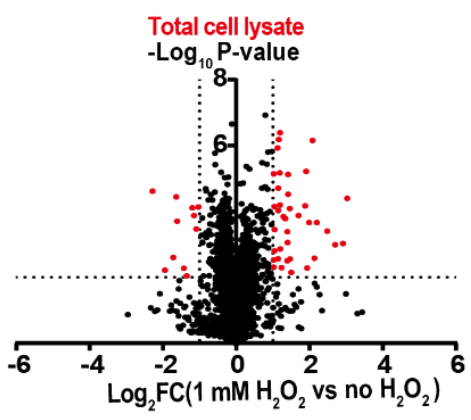

J

\begin{tabular}{|c|c|}
\hline \multicolumn{2}{|c|}{ The optimum experimental Conditions } \\
\hline $\mathrm{C}_{\mathrm{B} \times \mathrm{P}}(\mu \mathrm{M})$ & 200 \\
\hline $\mathrm{C}_{\mathrm{H}_{2} \mathrm{O}_{2}}$ (mM, final) & 1 \\
\hline $\mathrm{CHRP}(\mathrm{mg} / \mathrm{ml}$, final) & 1 \\
\hline$(150-250$ units/mg solid, using pyrogallol) $)$ & 0.25 \\
\hline Labeling time (min) & 1 \\
\hline $\begin{array}{c}\text { Volume of avidin beads } \\
(\sim 1.2 \mathrm{mg} \text { labeled lysate) }\end{array}$ & $40 \mu \mathrm{\mu l}$ \\
\hline Labeling temperature & $25^{\circ} \mathrm{C}$ \\
\hline
\end{tabular}

Figure S3: Workflow optimization of PECSL technology for HeLa cell surfaceome profiling. 
The concentration of labeling probe, $\mathrm{B} \times \times \mathrm{P}$, was assessed using $(A)$ western blotting and $(B)$ singlerun LC-MS/MS measurement in HeLa cells. (C) Comparison of the enriched proteins between the control (without BxxP) and experimental ( $200 \mu \mathrm{M} B \times \times P)$ cell samples by LFQ method. Three biological replicate samples were prepared and each sample was analyzed with one technical run. Fold change (x-axis) is shown as $\log 2$, and p; P -value, which was calculated using the software of Perseus, is shown as $-\log 10$. Red dots are cell-surface proteins by GO annotation. Details also could be seen in Table S2. (D) Cellular component classification was conducted by GO enrichment analysis according to cellular component for the up-regulated proteins $(\geq 2$-fold, p-value $<0.05$ ) in labeling probe-treated experimental groups. $(E)$ A proper volume of avidin beads for a certain amount of total cell lysate was evaluated with single-run LC-MS/MS measurement in HeLa cells. The concentration of $\mathrm{H}_{2} \mathrm{O}_{2}$ from $0.1 \mathrm{mM}$ to $100 \mathrm{mM}$ was assessed by 1 min-PECSL labeling $(0.25$ $\mathrm{mg} / \mathrm{ml}$ HRP final, $200 \mu \mathrm{M} \mathrm{B} \times \times \mathrm{P})$ using $(F)$ western blotting and $(G)$ single-run LC-MS/MS measurement in HeLa cells. $(H)$ A LFQ proteomic experiment was employed to compare the whole lysate proteins between the control (without $\mathrm{H}_{2} \mathrm{O}_{2}$ ) and experimental $\left(1 \mathrm{mM} \mathrm{H}_{2} \mathrm{O}_{2}\right.$ ) cell samples to determine the oxidative damage from 1 min incubation with $1 \mathrm{mM} \mathrm{H}_{2} \mathrm{O}_{2}$. Three biological replicates were prepared and each sample was analyzed with one technical run. String analysis was performed for the 42 up-regulated proteins ( $\geqslant 2$-fold, p-value $<0.05$ ) in $\mathrm{H}_{2} \mathrm{O}_{2}$-treated experimental groups. The networks were visualized using Cytoscape v.3.6.0.. The detailed information could be seen Table S3. $(J)$ The optimum experimental conditions for PECSL technology. 


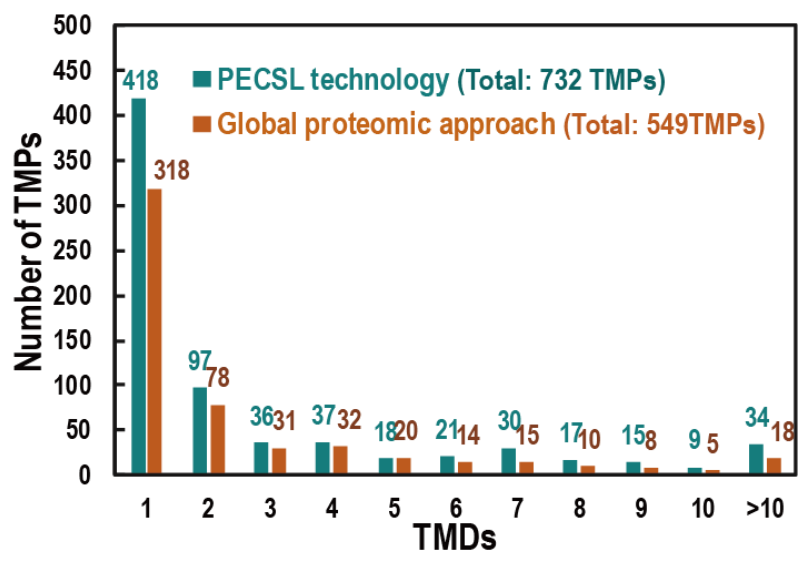

343 Figure S4: Distribution of transmembrane domains (TMDs) of transmembrane proteins (TMPs) in the PECSL data and global proteomic data in HeLa cells. The software of TMHMM and Phobius were utilized here to predict the TMPs. 

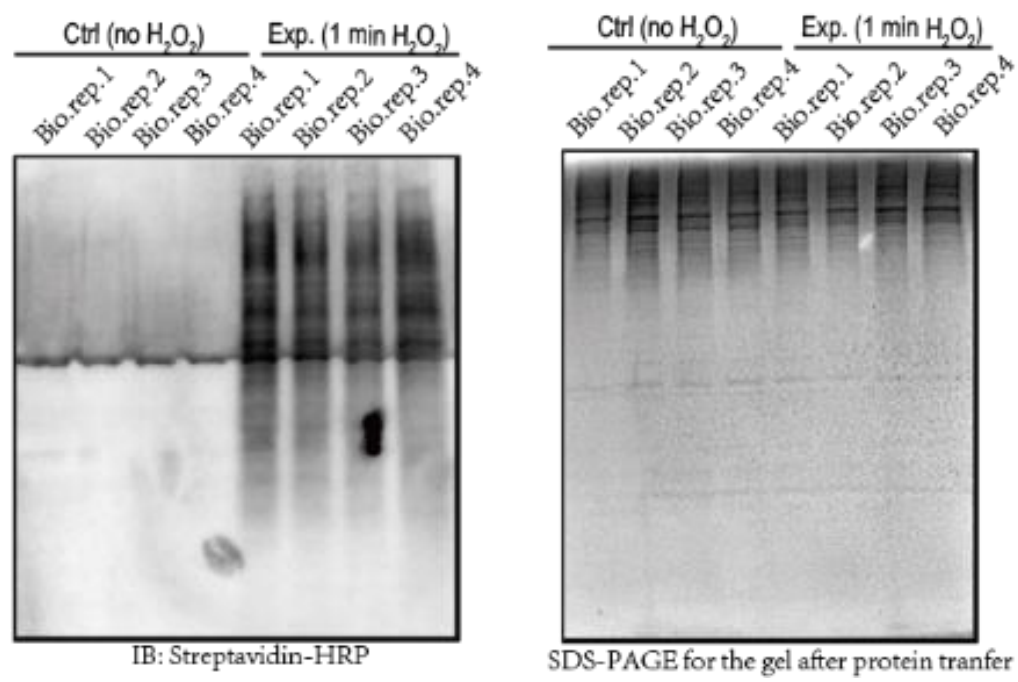

Figure S5: Assessment of the biotinylation of experimental $\left(\mathrm{H}_{2} \mathrm{O}_{2}\right.$ treatment for 1 min) and negative (with $\mathrm{H}_{2} \mathrm{O}_{2}$ treatment) control cell samples using western blotting and the gel after protein transfer was stained by Coomassie Brilliant Blue method as protein level control. Four biological replicates were performed. 
A
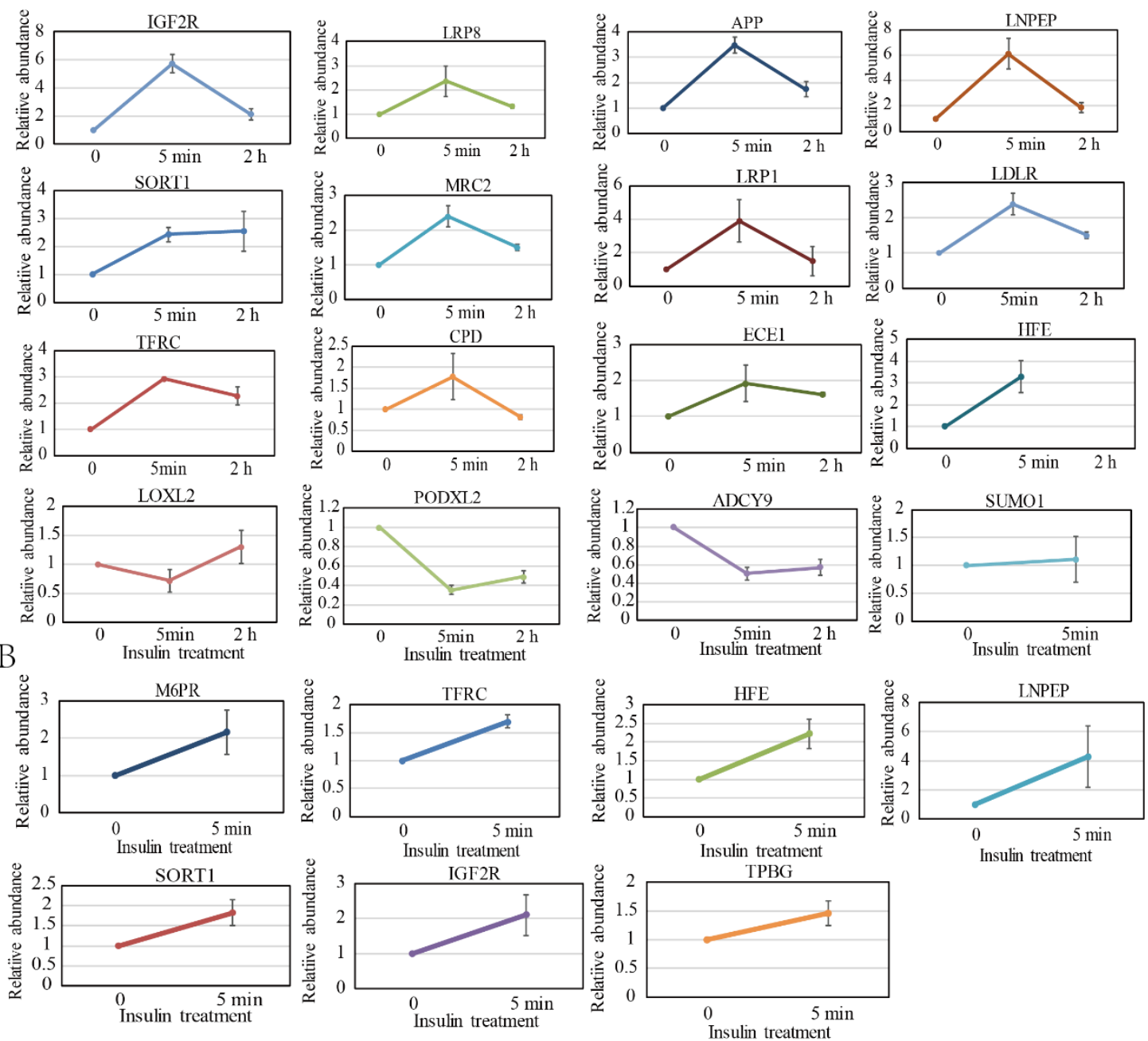

Figure S6: The bar charts to show the intensities of quantified insulin-regulated proteins by PECSL technology $(A)$ and amine-reactive cell surface biotinyaltion $(B)$. Protein intensities for insulin-regulated proteins for each biological replicate at each time point were median of the three LC-MS/MS measurement and then converted to fold changes over control median intensities of the three biological replicates. The median fold changes of the three biological replicates were set as the final fold change at each time point for insulin-regulated proteins. 

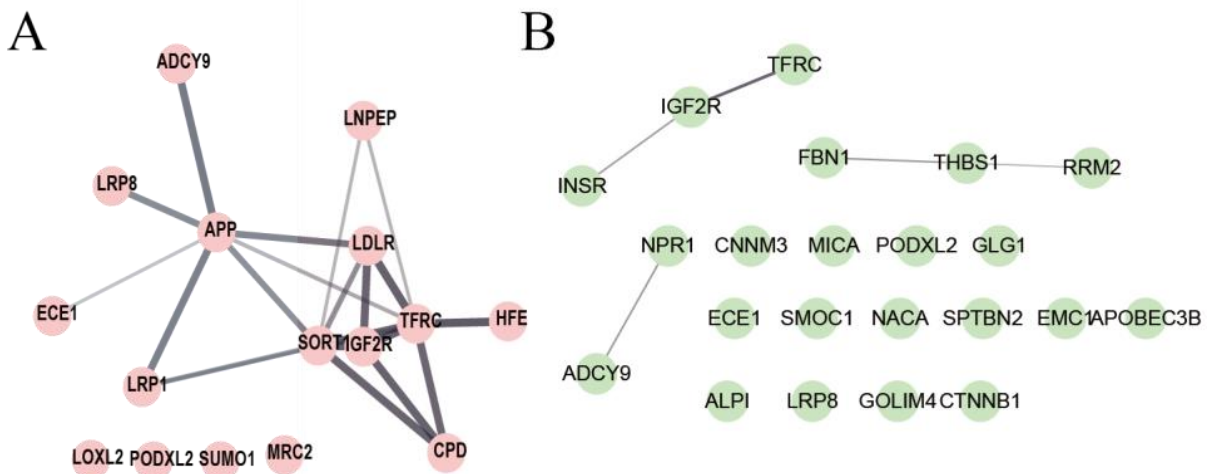

Figure S7: String analysis for the 'early' and 'late' insulin-regulated proteins. The network was visualized using Cytoscape v.3.6.0. 
Table S4: The peptide recovery assessment for $1 \mathrm{mg}$ labeled HeLa cell samples by PECSL technology. Four biological replicate samples were prepared. The enriched peptides of each sample were re-suspended in $100 \mu \mathrm{l}$ of $0.1 \%$ formic acid and analyzed by NanoDrop 2000 for three times. It was determined that $7.9 \pm 0.17 \mu \mathrm{g}(\mathrm{n}=4)$ peptides were enriched by PECSL technology from $\sim 1$ mg labeled HeLa cell samples.

\begin{tabular}{|c|c|c|c|c|c|c|c|}
\hline Date & Sample Name & $\begin{array}{c}\text { Protein } \\
(\mathrm{mg} / \mathrm{mL})\end{array}$ & A205 & A280 & Method & $\begin{array}{c}\text { Baseline } \\
\text { Correction (nm) }\end{array}$ & $\begin{array}{c}\text { Baseline } \\
\text { Absorbance }\end{array}$ \\
\hline 10/31/2020 5:31:04 PM & Blank, 0.1\% FA & 0.001 & 0.023 & 0.012 & 31 & 340 & -0.011 \\
\hline 10/31/2020 5:31:58 PM & PECSL_RT1min_bio.rep.1_run1 & 0.078 & 2.405 & 0.097 & 31 & 340 & 0.048 \\
\hline 10/31/2020 5:32:34 PM & PECSL_RT1min_bio.rep.1_run2 & 0.077 & 2.372 & 0.095 & 31 & 340 & 0.028 \\
\hline 10/31/2020 5:33:02 PM & PECSL_RT1min_bio.rep.1_run3 & 0.074 & 2.308 & 0.089 & 31 & 340 & 0.006 \\
\hline 10/31/2020 5:33:27 PM & PECSL_RT1min_bio.rep.2_run1 & 0.059 & 1.818 & 0.096 & 31 & 340 & -0.021 \\
\hline 10/31/2020 5:34:32 PM & PECSL_RT1min_bio.rep.2_run2 & 0.058 & 1.793 & 0.08 & 31 & 340 & 0.041 \\
\hline 10/31/2020 5:35:12 PM & PECSL_RT1min_bio.rep.2_run3 & 0.061 & 1.886 & 0.075 & 31 & 340 & 0.039 \\
\hline 10/31/2020 5:35:47 PM & PECSL_RT1min_bio.rep.3_run1 & 0.092 & 2.867 & 0.127 & 31 & 340 & 0.01 \\
\hline 10/31/2020 5:36:22 PM & PECSL_RT1min_bio.rep.3_run2 & 0.091 & 2.817 & 0.131 & 31 & 340 & -0.014 \\
\hline 10/31/2020 5:36:48 PM & PECSL_RT1min_bio.rep.3_run3 & 0.087 & 2.699 & 0.119 & 31 & 340 & 0.033 \\
\hline 10/31/2020 5:37:27 PM & PECSL_RT1min_bio.rep.4_run1 & 0.083 & 2.578 & 0.118 & 31 & 340 & -0.022 \\
\hline 10/31/2020 5:38:01 PM & PECSL_RT1min_bio.rep.4_run2 & 0.079 & 2.435 & 0.111 & 31 & 340 & 0.018 \\
\hline 10/31/2020 5:38:33 PM & PECSL_RT1min_bio.rep.4_run3 & 0.083 & 2.574 & 0.109 & 31 & 340 & -0.007 \\
\hline
\end{tabular}


Table S7: The PECSL data and multiple surfaceome data generated by using different enrichment strategies were analyzed with SurfaceGenie.

\begin{tabular}{|c|c|c|c|c|c|c|c|}
\hline $\begin{array}{c}\text { Total } \\
\text { proteins }\end{array}$ & $\left|\begin{array}{c}\text { SPC score } \\
3,4\end{array}\right|$ & $\begin{array}{c}\text { SPC score } \\
1,2\end{array}$ & $\mid \begin{array}{c}\text { SPC score } \\
0\end{array}$ & Target residues & annotation & Mass spectrometer & Ref. \\
\hline 815 & $116(14.2 \%)$ & $131(16.3 \%)$ & $568(70.5 \%)$ & $\begin{array}{c}\text { glycan chains (Lectin Affinity } \\
\text { Chromatography and } \\
\text { Glycocapture } \\
\text { Approaches) }\end{array}$ & $\begin{array}{l}\text { protein-level } \\
\text { enrichment }\end{array}$ & $\begin{array}{c}\text { LTQ ion trap mass } \\
\text { spectrometer (Thermo } \\
\text { Finnigan, San Jose, CA) }\end{array}$ & 12 \\
\hline 219 & $142(64.8 \%)$ & $38(17.4 \%)$ & $39(17.8 \%)$ & glycan chains & \multirow{2}{*}{$\begin{array}{l}\text { Peptide-level } \\
\text { enrichment }\end{array}$} & \multirow{2}{*}{$\begin{array}{l}\text { Finnigan LTQ Orbitrap } \\
\text { MS (ThermoFisher } \\
\text { Scientific) }\end{array}$} & \multirow[b]{2}{*}{13} \\
\hline 742 & $198(26.7)$ & $127(17.1 \%)$ & $417(56.2 \%)$ & lysine & & & \\
\hline 291 & $144(49.5 \%)$ & $64(22.0 \%)$ & $82(28.2 \%)$ & carboxyl groups & \multirow{2}{*}{$\begin{array}{l}\text { Protein-level } \\
\text { enrichment }\end{array}$} & \multirow{2}{*}{\begin{tabular}{|} 
Q Exactive Orbitrap/LTQ- \\
Orbitrap (ThermoFisher \\
Scientific)
\end{tabular}} & \multirow[b]{2}{*}{14} \\
\hline 530 & $118(22.3 \%)$ & $84(15.8 \%)$ & $328(61.9 \%)$ & lysine & & & \\
\hline 469 & $325(69.3 \%)$ & $111(23.7 \%)$ & $33(7 \%)$ & glycan chains & \begin{tabular}{|} 
Only glycopeptide with \\
glycosylation sites for \\
identification
\end{tabular} & \begin{tabular}{|c} 
LTQ Orbitrap Elite \\
(ThermoFisher Scientific)
\end{tabular} & 15 \\
\hline 2236 & $264(11.8 \%)$ & $598(26.7 \%)$ & $\begin{array}{c}1374 \\
(61.4 \%)\end{array}$ & \begin{tabular}{|c|} 
Sucrose Density \\
Gradient Centrifugation (50\%- \\
30\% Zonal Fraction)
\end{tabular} & & \multirow{5}{*}{$\begin{array}{c}\text { Q Exactive Orbitrap } \\
\text { (ThermoFisher Scientific) }\end{array}$} & \multirow{5}{*}{16} \\
\hline 2259 & $295(13.1 \%)$ & $521(23.1 \%)$ & $\begin{array}{c}1443 \\
(63.9 \%)\end{array}$ & \multirow{2}{*}{$\begin{array}{c}\text { Sucrose Density } \\
\text { Gradient Centrifugation (50\%- } \\
10 \% \text { Zonal Fraction) }\end{array}$} & & & \\
\hline 7620 & $596(7.8 \%)$ & 1035 (13.6\%) & $\begin{array}{c}5989 \\
(78.6 \%)\end{array}$ & & $\begin{array}{c}\text { Fractionated into } 24 \\
\text { samples by immobilized } \\
\text { pH gradient-isoelectric } \\
\text { focusing }\end{array}$ & & \\
\hline 1087 & $110(10.1 \%)$ & $132(12.1 \%)$ & $845(77.7 \%)$ & lysine (BioID) & \multirow{2}{*}{$\begin{array}{l}\text { Protein-level } \\
\text { enrichment }\end{array}$} & & \\
\hline 834 & $156(18.7 \%)$ & $149(17.9 \%)$ & $529(63.4 \%)$ & $\begin{array}{c}\text { lysine (BioID and Sucrose } \\
\text { Density Gradient Centrifugation) }\end{array}$ & & & \\
\hline 2932 & $309(10.5 \%)$ & $425(14.5 \%)$ & $\begin{array}{c}2198 \\
(75.0 \%)\end{array}$ & lysine & $\begin{array}{l}\text { Protein-level } \\
\text { enrichment }\end{array}$ & 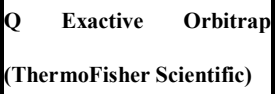 & 17 \\
\hline 2684 & $302(11.3 \%)$ & $411(15.3 \%)$ & $1971(73.4)$ & \multirow{4}{*}{ electron-rich amino acids, mainly } & \multirow{2}{*}{$\begin{array}{l}\text { Protein-level enrichment } \\
\text { (Identification data) }\end{array}$} & \multirow{5}{*}{ 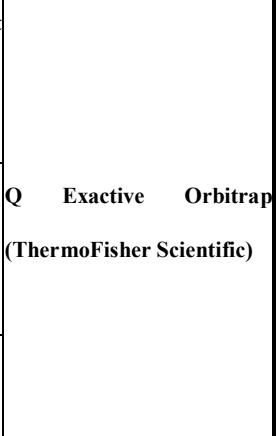 } & \multirow{5}{*}{ PECSL } \\
\hline $\begin{array}{c}156 \\
(\text { PSMs }>100)\end{array}$ & $46(29.5 \%)$ & $19(12.2 \%)$ & $65(58.3 \%)$ & & & & \\
\hline 1757 & $230(13.1 \%)$ & $275(15.7 \%)$ & $\begin{array}{c}505 \\
(71.2 \% \%)\end{array}$ & & \multirow{2}{*}{$\begin{array}{l}\text { Protein-level } \\
\text { enrichment, } \\
\text { (quantification data) }\end{array}$} & & \\
\hline 731 & $202(27.6 \%)$ & $124(17.0 \%)$ & $405(55.4 \%)$ & & & & \\
\hline 3510 & $118(3.4 \%)$ & $386(11.0 \%)$ & $\begin{array}{c}3006 \\
(85.6 \%)\end{array}$ & (whole cell lysate) & & & \\
\hline
\end{tabular}




\section{REFERENCE}

1. Li, Y.; Wang, Y.; Mao, J.; Yao, Y.; Wang, K.; Qiao, Q.; Fang, Z.; Ye, M., Sensitive profiling of cell surface proteome by using an optimized biotinylation method. J Proteomics 2019, 196, 33-41.

2. Elia, G., Cell surface protein biotinylation for SDS-PAGE analysis. Methods Mol Biol 2019, 1855, 449-459.

3. Kasvandik, S.; Sillaste, G.; Velthut-Meikas, A.; Mikelsaar, A. V.; Hallap, T.; Padrik, P.; Tenson, T.; Jaakma, U.; Koks, S.; Salumets, A., Bovine sperm plasma membrane proteomics through biotinylation and subcellular enrichment. Proteomics 2015, 15 (11), 1906-1920.

4. Penaranda, M. M. D.; Jensen, I.; Tollersrud, L. G.; Bruun, J. A.; Jorgensen, J. B., Profiling the atlantic salmon $\operatorname{IgM}(+)$ B cell surface proteome: novel information on teleost fish B cell protein repertoire and identification of potential B cell markers. Front. Immunol. 2019, 10, 19.

5. Obermann, J.; Wagner, F.; Kociaj, A.; Zambusi, A.; Ninkovic, J.; Hauck, S. M.; Chapouton, P., The surface proteome of adult neural stem cells in Zebrafish unveils long-range cell-cell connections and age-related changes in responsiveness to IGF. Stem Cell Reports 2019, 12 (2), 258-273.

6. Bundgaard, L.; Stensballe, A.; Elbaek, K. J.; Berg, L. C., Mapping of equine mesenchymal stromal cell surface proteomes for identification of specific markers using proteomics and gene expression analysis: an in vitro cross-sectional study. Stem Cell Research \& Therapy 2018, 9, 10.

7. Kumar, V.; Nguyen, T. B.; Toth, B.; Juhasz, V.; Unadkat, J. D., Optimization and application of a biotinylation method for quantification of plasma membrane expression of transporters in cells. AAPS J 2017, 19 (5), 1377-1386.

8. $\quad$ Steinberg, F.; Gallon, M.; Winfield, M.; Thomas, E. C.; Bell, A. J.; Heesom, K. J.; Tavare, J. M.; Cullen, P. J., A global analysis of SNX27-retromer assembly and cargo specificity reveals a function in glucose and metal ion transport. Nat. Cell Biol. 2013, 15 (5), 461-+.

9. PosthumaDeBoer, J.; Piersma, S. R.; Pham, T. V.; van Egmond, P. W.; Knol, J. C.; Cleton-Jansen, A. M.; van Geer, M. A.; van Beusechem, V. W.; Kaspers, G. J. L.; van Royen, B. J.; Jimenez, C. R.; Helder, M. N., Surface proteomic analysis of osteosarcoma identifies EPHA2 as receptor for targeted drug delivery. Br. J. Cancer 2013, 109 (8), 2142-2154.

10. Biller, L.; Matthiesen, J.; Kuhne, V.; Lotter, H.; Handal, G.; Nozaki, T.; Saito-Nakano, Y.; Schumann, M.; Roeder, T.; Tannich, E.; Krause, E.; Bruchhaus, I., The Cell Surface Proteome of Entamoeba histolytica. Mol Cell Proteomics 2014, 13 (1), 132-144.

11. Hollmann, F.; Arends, I. W. C. E., Enzyme Initiated Radical Polymerizations. Polymers 2012, 4 (1), 759-793.

12. McDonald CA; Yang JY; Marathe V; Yen TY; BA, M., Combining results from lectin affinity chromatography and glycocapture approaches substantially improves the coverage of the glycoproteome. Mol Cell Proteomics 2009, 15.

13. Nagano, K.; Shinkawa, T.; Kato, K.; Inomata, N.; Yabuki, N.; Haramura, M., Distinct cell surface proteome profiling by biotin labeling and glycoprotein capturing. J Proteomics 2011, 74 (10), 1985-93. 14. Ozkan Kucuk, N. E.; Sanal, E.; Tan, E.; Mitchison, T.; Ozlu, N., Labeling carboxyl groups of surface-exposed proteins provides an orthogonal approach for cell surface isolation. J Proteome Res 2018, 17 (5), 1784-1793.

15. Sun, F.; Suttapitugsakul, S.; Wu, R., Enzymatic Tagging of Glycoproteins on the Cell Surface for Their Global and Site-Specific Analysis with Mass Spectrometry. Anal Chem 2019, 91 (6), 4195-4203. 16. Akdag, M.; Yunt, Z. S.; Kamacioglu, A.; Qureshi, M. H.; Akarlar, B. A.; Ozlu, N., Proximal Biotinylation-Based Combinatory Approach for Isolating Integral Plasma Membrane Proteins. $J$ 
Proteome Res 2020, 19 (8), 3583-3592. 